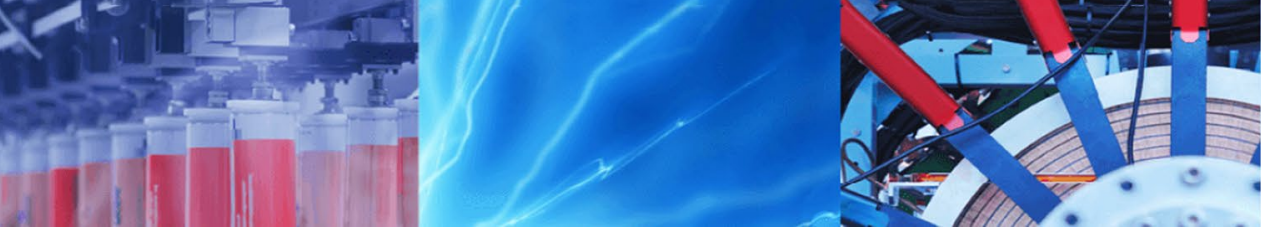

Research Article

\title{
Effects of Si on the formation of intermetallic phases in alloying reaction between iron substrate and liquid $\mathrm{Zn}$ containing $0.2 \mathrm{wt} \% \mathrm{Al}$
}

\author{
Satoru Kobayashi ${ }^{1}$ D
}

C) Springer Nature Switzerland AG 2018

\begin{abstract}
The Fe-Zn and Fe-Al-based alloying phases are formed on galvanized/galvannealed steels which are extensively used as automobile bodies. This paper investigated the effects of $\mathrm{Si}$ on the formation of intermetallic phases in the alloying reaction between an iron substrate and liquid $\mathrm{Zn}$ containing $0.2 \mathrm{wt} \% \mathrm{Al}$ and partitioning of Si between the phases. The addition of $\mathrm{Si}$ to the iron substrate was found to scarcely influence the formation and morphology of the $\mathrm{Fe}_{2} \mathrm{Al}_{5}$ intermetallic phase layer but to reduce the amount of the $\delta_{1}-\mathrm{FeZn}_{7-10}$ intermetallic phase layer at the substrate/liquid interface and to disperse the phase as grains in the $\mathrm{Zn}-0.2 \mathrm{wt} \%$ Al coating matrix. STEM-EDS analysis demonstrates that Si partitions less into the $\mathrm{Fe}_{2} \mathrm{Al}_{5}$ and the $\delta_{1}$ phases than into the iron substrate. Enrichment of $\mathrm{Si}$ around an Si-depleted Fe- $\mathrm{Zn}$ intermetallic phase product was also observed in the beginning of the alloying reaction. The results obtained allow us to explain the effect of $\mathrm{Si}$ on the intermetallic phase formation in terms of a difficulty in nucleating the $\delta_{1}$ phase at the substrate/liquid interface.
\end{abstract}

Keywords Fe-Zn-based intermetallics · Alloying reaction · Alloying effect

\section{Introduction}

Hot-dip galvanized/galvannealed steels are extensively used for steel sheets as automobile bodies because of good productivity and excellent corrosion resistance due to its sacrificial anodic effect [1]. The Fe-Zn and Fe-Albased alloying (intermetallic) phases are known to be formed as a result of the reaction between $\mathrm{Fe}$ in the steel substrate and $\mathrm{Zn}(\mathrm{Al})$ in the galvanizing bath during a hotdip galvanizing process and/or a subsequent annealing process [2]. Since the mechanical properties of the alloying phases and the steel substrate/coating interface highly depend on the types, morphologies and thickness of the phases formed, it is important to understand the mechanisms of the alloying reaction.

According to the previous researches on the alloying reaction [2-4], the sequence of the reaction is reported as follows. $\mathrm{An} \mathrm{Fe}_{2} \mathrm{Al}_{5}$-type intermetallic phase layer firstly forms at the interface between the steel substrate and the liquid $\mathrm{Zn}$-Al. It is generally considered that this Fe-Al phase acts as a barrier for the reaction between Fe and $Z n$. $\mathrm{Fe}-\mathrm{Zn}$-based intermetallic phase layers subsequently form in a way to break the $\mathrm{Fe}_{2} \mathrm{Al}_{5}$ phase layer at grain boundaries of the ferrite phase in the steel substrate. This reaction is called "outburst reaction" due to its outward growth by breaking the $\mathrm{Fe}_{2} \mathrm{Al}_{5}$ phase barrier layer. The phase constituents in the outburst products are reported to depend on the reaction temperature and the presence/absence of $\mathrm{Al}$ in the $\mathrm{Zn}$ bath, but it is known that the $\delta_{1}-\mathrm{FeZn}_{7-10}$ phase is formed as main phase [2-4] when the reaction temperature is higher than $485^{\circ} \mathrm{C}[2]$. The $\Gamma-\mathrm{Fe}_{3} \mathrm{Zn}_{10}$ phase is subsequently formed in between the $\delta_{1}$ phase and the substrate.

It has been reported in recent years that the alloying reaction in the galvanizing/annealing process is retarded by the addition of $\mathrm{Si}$ to the steel substrates, which is a serious

Satoru Kobayashi, kobayashi.s@mtl.titech.ac.jp| ${ }^{1}$ Department of Materials Science and Engineering, School of Materials and Chemical Technology, Tokyo Institute of Technology, 2-12-1 S8-3 Ookayama, Meguro-ku, Tokyo 152-8552, Japan. 
problem in the production of galvanized/galvannealed high-strength steels. Tobiyama et al. [5] reported that the retardation of the reaction is due to the formation of Si oxide particles on the steel substrate during a reduction process, which may reduce the contact area between the substrate and the liquid. Yasui et al. [6] found that the retardation took place even in the absence of oxide particles, and reported that it can be explained by the solid solution of $\mathrm{Si}$ into the $\mathrm{Fe}-\mathrm{Al}$ intermetallic phase to enhance its barrier effect and/ or the solid solution into the $\delta_{1}$ phase to retard the interdiffusion between Fe and $\mathrm{Zn}$ through the phase. The partitioning of Si into the intermetallic phases during the alloying reaction was, however, rarely reported [7-9], and the effect of $\mathrm{Si}$ on the retardation of the alloying reaction is therefore not fully understood especially in the absence of oxide particles on the substrate/coating interface.

In the present paper, effects of Si on the formation of intermetallic phases in an alloying reaction between an iron substrate and liquid $\mathrm{Zn}$ containing $0.2 \mathrm{wt} \% \mathrm{Al}$ and partitioning of $S i$ between the phases were investigated to understand the alloying reactions during hot-dip galvanizing and annealing of Si doped steels.

\section{Experimental procedures}

The chemical compositions of the iron alloys used as the substrate in the present study are listed in Table 1. The amount of alloying elements except Si was reduced as low as possible to make the investigation simple. The iron alloys are designated by their Si contents ( $0 \% \mathrm{Si}$ and $0.2 \%$ $\mathrm{Si}$ ) throughout this paper. The iron alloys were cold rolled to sheets with a thickness of $0.8 \mathrm{~mm}$ and then galvanized. In the galvanizing treatment the sheets were reduced in an $\mathrm{N}_{2}-15 \% \mathrm{H}_{2}$ atmosphere (with a dew point of $-45^{\circ} \mathrm{C}$ ) at $800{ }^{\circ} \mathrm{C}$ for $40 \mathrm{~s}$, then cooled, dipped into a bath with $\mathrm{Zn}-0.2 \% \mathrm{Al}$ in composition at $450^{\circ} \mathrm{C}$ for $3 \mathrm{~s}$ and followed by $\mathrm{N}_{2}$ gas cooling. The galvanized sheets were subsequently cleaned with ethanol and then annealed in a salt bath at $500^{\circ} \mathrm{C}$ for $1 \mathrm{~min}$, followed by water quenching.

The microstructures of the galvanized and annealed samples were observed with a field emission type scanning electron microscope (FESEM) and a scanning transmission electron microscope (STEM). The samples for FESEM observations were prepared by grinding down to $1 \mu \mathrm{m} \mathrm{Al} \mathrm{O}_{3}$ polishing suspension and followed by either polishing using oxide polishing suspension or ion milling with a voltage/current condition of $6 \mathrm{kV} / 140 \mu \mathrm{A}$. The samples for STEM observations were prepared by a pick-up technique using an FIB equipment with a final milling/ cleaning condition of $5 \mathrm{kV} / \sim 50 \mathrm{pA}$. The chemical compositions of the elements in the samples were analyzed with energy dispersive spectroscopy (EDS) equipped on FESEM with $20 \mathrm{kV}$ and STEM with $200 \mathrm{kV}$. Electron backscattering diffraction (EBSD) patterns were acquired to support the identification of the phases present under a voltage of $20 \mathrm{kV}$ with an acquisition time of a few seconds which is longer than a usual time for typical orientation mapping. The EBSD patterns were analyzed by TSL software.

\section{Results and discussion}

\subsection{Formation of intermetallic phases in Si free/ doped iron substrates}

Figure 1 compares the microstructures formed at the substrate/coating interface in the $0 \% \mathrm{Si}$ and $0.2 \% \mathrm{Si}$ steels
Table 1 The chemical compositions of the iron-based substrates used in the present study. Sol Al means Al in solid solution in the steels

Fig. 1 Backscattered electron images of the samples after hot-dip galvanizing: a $0 \% \mathrm{Si}, \mathbf{b}$ $0.2 \% \mathrm{Si}$, showing the formation of $\mathrm{Fe}-\mathrm{Al}$-based intermetallic phase layer along the substrate/coating interfaces in the center. Horizontal lines are formed by milling with FIB

\begin{tabular}{llllllllll}
\hline Steel & \multicolumn{9}{l}{ Chemical composition (wt\%) } \\
\cline { 2 - 9 } & $\mathrm{C}$ & $\mathrm{Si}$ & $\mathrm{Mn}$ & $\mathrm{P}$ & $\mathrm{S}$ & \multicolumn{1}{c}{ SolAl } & $\mathrm{N}$ & $\mathrm{O}$ & $\mathrm{Fe}$ \\
\hline $0 \% \mathrm{Si}$ & 0.001 & 0.01 & $<0.01$ & $<0.001$ & 0.001 & 0.002 & 0.0010 & 0.008 & Bal. \\
$0.2 \% \mathrm{Si}$ & 0.001 & 0.11 & $<0.01$ & $<0.001$ & 0.001 & $<0.001$ & 0.0009 & 0.006 & Bal. \\
\hline
\end{tabular}

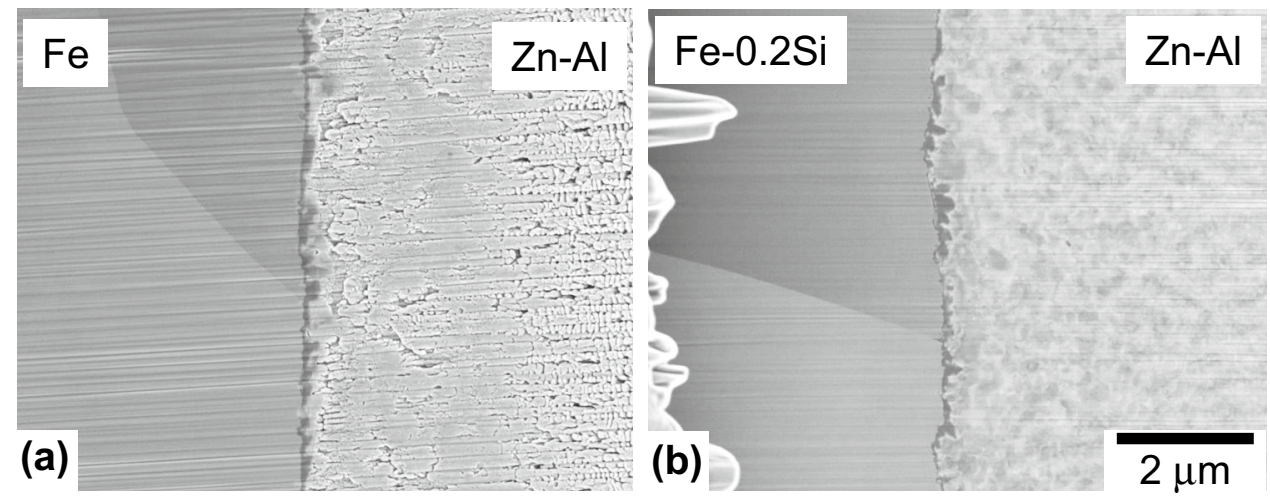


Fig. 2 Backscattered electron images of the samples after a hot-dip galvanizing process and a subsequent annealing process: a $0 \% \mathrm{Si}, \mathbf{b} 0.2 \% \mathrm{Si}$, showing intermetallic phase layers. It is noted that the $\mathrm{Zn}$ coating layer is not imaged in the micrographs
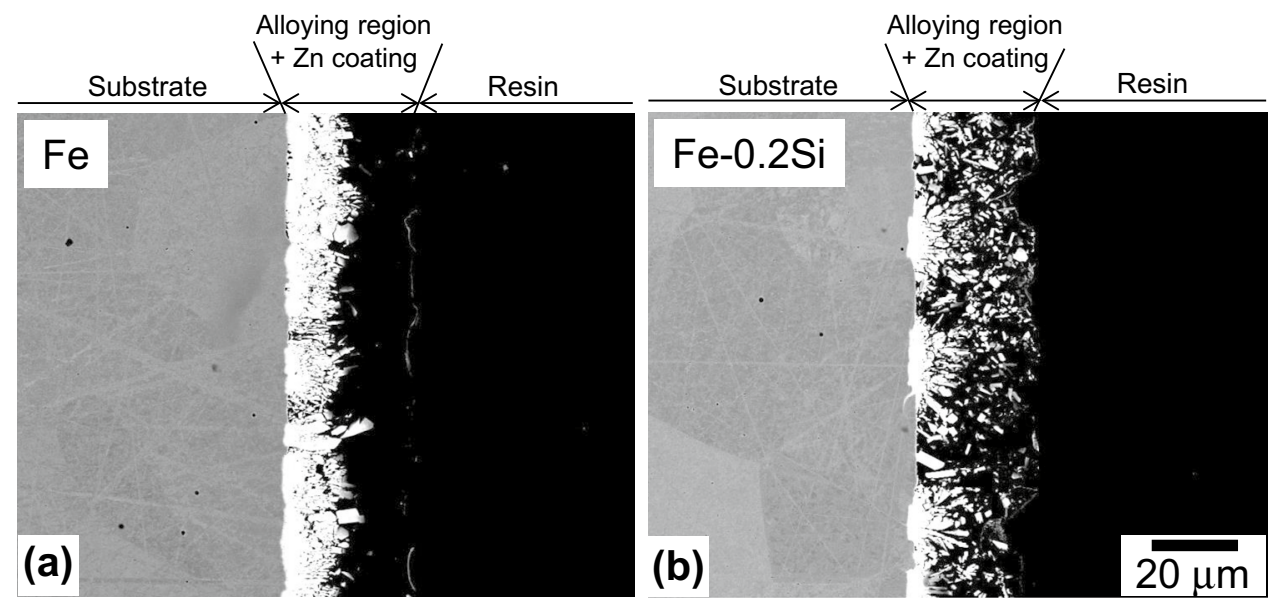
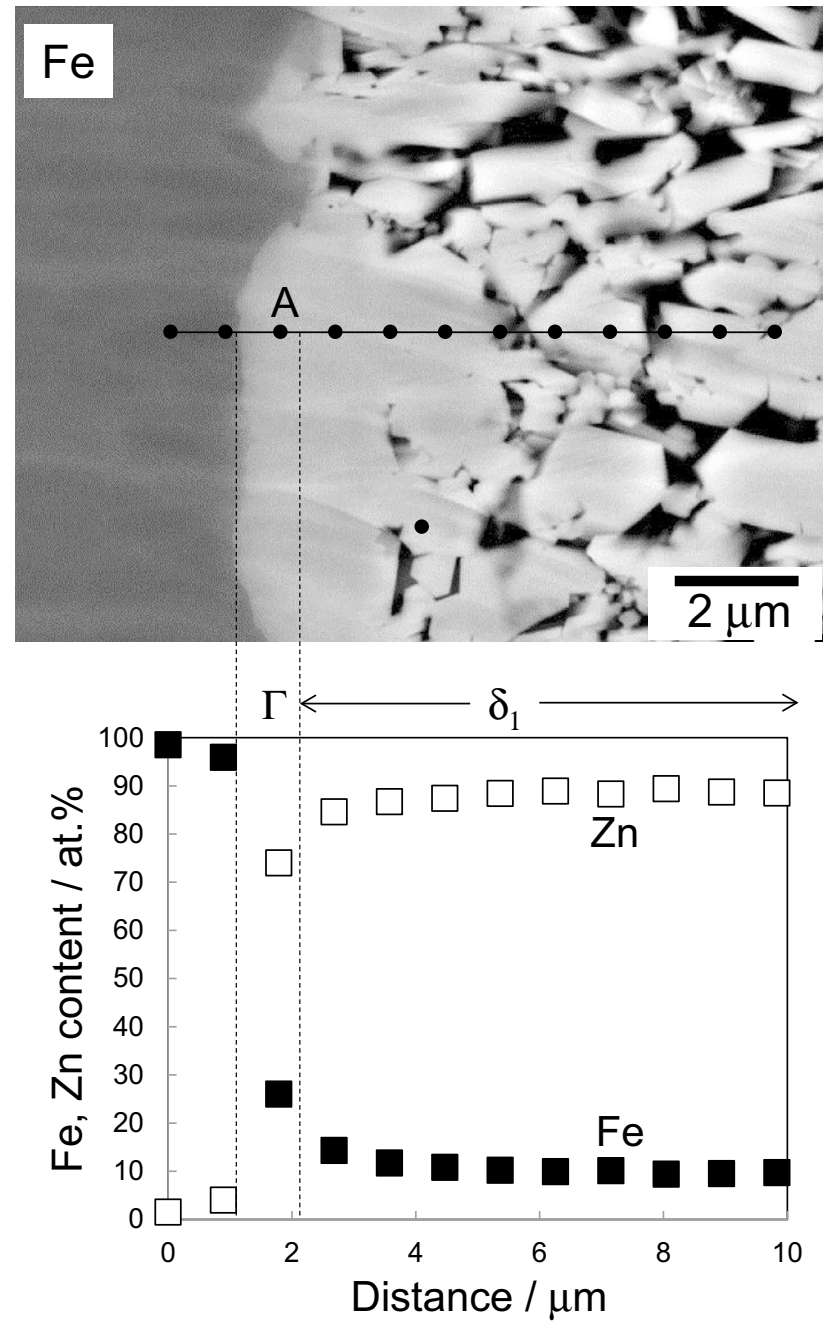

Fig. 3 EDS line profile along the line indicated in the BSE image taken from the $0 \%$ Si sample after annealing for $1 \mathrm{~min}$ at $500^{\circ} \mathrm{C}$

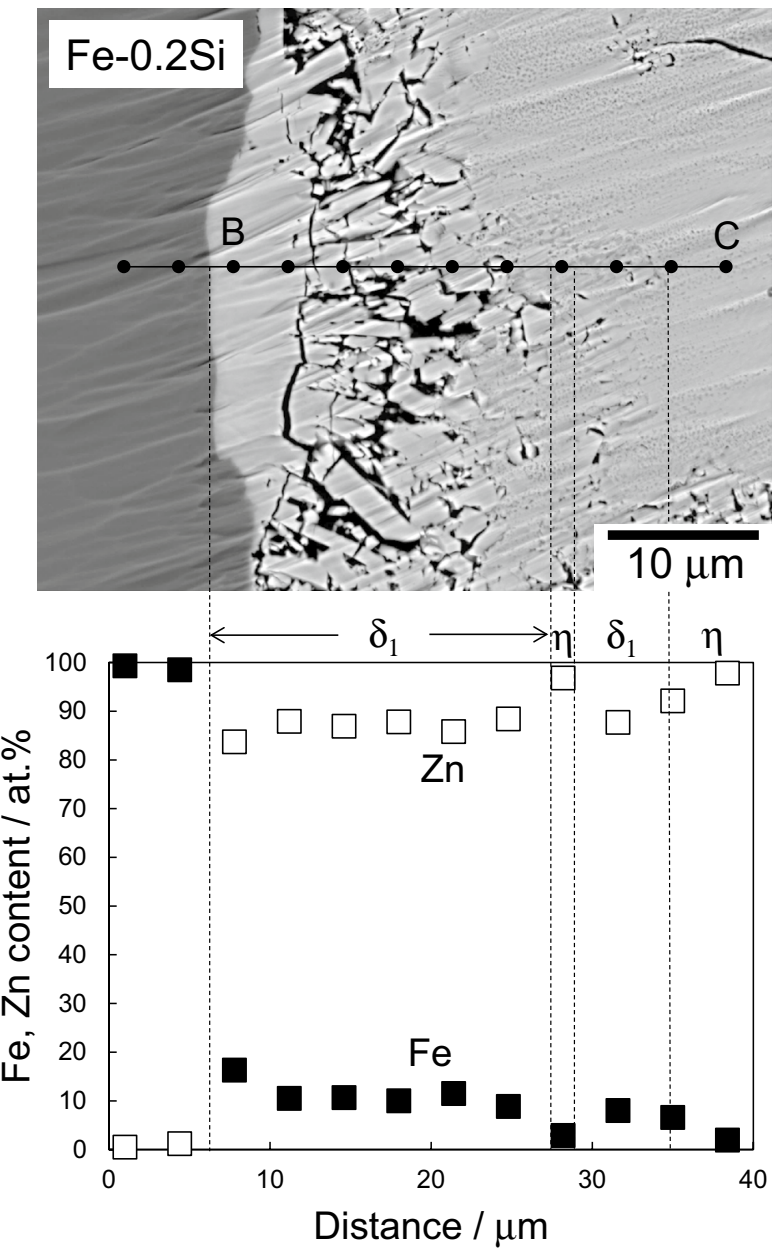

Fig. 4 EDS line profile along the line indicated in the BSE image taken from the $0.2 \%$ Si sample after annealing for $1 \mathrm{~min}$ at $500^{\circ} \mathrm{C}$ 
after galvanizing. An alloying layer with relatively dark contrast is formed along the interface in the both samples. The layer is Al rich, as measured by EDS analysis (see Fig. 7), and is therefore deduced to be of the $\mathrm{Fe}_{2} \mathrm{Al}_{5}$ intermetallic phase. The interface between the $\mathrm{Fe}_{2} \mathrm{Al}_{5}$ phase and the coating region is bumpy, and the thickness of the layer is about $300 \mathrm{~nm}$ in maximum along the direction perpendicular to the substrate/coating interface. It is found from wide area observation that the thickness and the morphology of the $\mathrm{Fe}_{2} \mathrm{Al}_{5}$ phase are similar in the two samples.

Figure 2 displays the distribution of alloying regions formed on the two types of iron substrates after annealing. It can be clearly seen that the alloying regions with a bright contrast are formed in the both steels, but their morphologies and distribution are different. In the $0 \%$ Si the regions are formed in a continuous and condensed manner and are attached to the iron substrate. An averaged thickness of the regions in the $0 \%$ Si was estimated to be $\sim 15 \mu \mathrm{m}$. In the $0.2 \% \mathrm{Si}$, on the other hand, the regions are formed in a dispersed manner. The amount of the alloying phase regions attached to the substrate is obviously less than that in the $0 \% \mathrm{Si}$ and the regions exist separately with each other on the substrate. It is also recognized that a number of a few micron-sized alloying phase grains are dispersed in the $\mathrm{Zn}-0.2 \% \mathrm{Al}$ coating matrix.

Figures 3 and 4 show examples of EDS analysis along the alloying regions in the $0 \% \mathrm{Si}$ and $0.2 \% \mathrm{Si}$ after annealing, respectively. In the $0 \% \mathrm{Si}$, it can be identified from the EDS profile and a reported chemical composition of Fe-Zn-based intermetallic phases $[1,5]$ that a $\sim 1 \mu \mathrm{m}$ thin layer of $\Gamma$ phase and a thick layer of $\delta_{1}$ phase are formed on the substrate side of the alloying regions. In the $0.2 \%$ $\mathrm{Si}$, the detected Fe contents in the alloying layers were in between 9 and 16 at.\%, which indicates that the main intermetallic phases formed is the $\delta_{1}$ phase and the formation of $\Gamma$ phase is limited. A fluctuation of the chemical compositions from $\sim 2$ to 9 at.\% detected in the Zn coating/alloying region demonstrates that the $\delta_{1}$ grains are dispersed in the matrix of $\mathrm{Zn}$ coating, which is designated as $\eta$ in the diagram.

EBSD patterns were taken from regions with different chemical compositions. Figure 5 shows examples of the patterns. The patterns taken from regions with the Fe content of $\sim 26$ at.\% are fit with predicted high-intensity EBSD lines that were calculated with the reported crystal symmetry and atom positions of the $\Gamma$ phase [10]. A pattern experimentally obtained from a region, marked by $A$ in Fig. 3a, and the pattern indexed are exemplified in Fig. 5a, $b$, respectively. The confidence index $(\mathrm{Cl})$ value defined in the software was $\sim 0.5$. EBSD patterns taken from regions whose chemical composition is around Fe-(87-91)at.\% $\mathrm{Zn}$ are found to show a hexagonal symmetry rather
Fig. 5 EBSD patterns obtained from the samples after galvanizing and annealing for $1 \mathrm{~min}$ at $500^{\circ} \mathrm{C}: \mathbf{a}, \mathbf{b}$ a $\Gamma$ phase pattern taken from a high Fe content region, marked by $\mathrm{A}$ in Fig. 3 in the $0 \% \mathrm{Si}$ sample, $\mathbf{c}$, $\mathbf{d}$ a pattern taken from a region, marked by $B$ in Fig. 4 , being assumed to be $\delta_{1}$ phase in the $0.2 \%$ Si sample, $\mathbf{e}, \mathbf{f}$ an $\eta-Z n$ phase pattern taken from a low Fe content region, marked by $\mathrm{C}$ in Fig. 4. These patterns are indexed using the crystallographic symmetric data summarized in Table 2. Confidence index (CI) values in $\mathbf{b}, \mathbf{c}$ and f are $0.51,0.34$ and 0.73 , respectively

than cubic $\left(\Gamma, \Gamma_{1}-\mathrm{Fe}_{11} Z \mathrm{n}_{39}\right)$ and monoclinic symmetries $\left(\zeta-F e Z n_{13}\right)$. A typical pattern and its indexed one are shown in Fig. $5 \mathrm{c}$, d. The $\delta_{1}$ phase is reported to have a complex hexagonal structure $\left(\mathrm{P \sigma}_{3} / \mathrm{mmc}\right)$ with 156 atoms in the unit cell [11-13]. The patterns are reasonably fit with the patterns which were calculated based on their crystallographic data $[12,13]$. It is, therefore, reasonable to identify that the alloying regions are of the $\delta_{1}$ phase based on the results obtained from EDS and EBSD. The patterns taken from low Fe content regions were found to show a perfect fit $(\mathrm{Cl}$ value: $~ 0.7)$ with the simulated patterns of the hcp structure, which demonstrates that the regions are of the $\eta-Z n$ phase. The crystallographic symmetry data used for indexing each phase in the EBSD analysis are summarized in Table 2.

\subsection{Partitioning of Si to the alloying phase}

Partitioning of Si to the intermetallic phases was investigated in order to understand the role of Si on the alloying reaction. Figure 6 shows an STEM image and EDS mapping performed for the rectangular areas $A$ and $B$ on a pick-up thin plate taken from the $0.2 \% \mathrm{Si}$ sample after galvanizing. These areas contain a thin $\mathrm{Fe}_{2} \mathrm{Al}_{5}$ phase layer and a globular region which is a product of outburst reaction. It can be seen in the area $\mathrm{A}$ that $\mathrm{Al}$ is enriched in the alloying layer along the substrate/coating interface, and $\mathrm{Si}$ is slightly diluted in the layer. The enrichment of $\mathrm{Zn}$ and $O$ is not recognized. It is recognized in the area $B$ that $\mathrm{Al}$ and $\mathrm{Zn}$ are enriched in the globular region, and $\mathrm{Si}$ is depleted in the globular region and enriched around the region on the substrate side. It should be mentioned that an Fe rich region is present on the right side of the globular region. The reason for the existence of this region is not clear, but it might be formed by the deposition of $\mathrm{Fe}$ sputtered from the substrate during the sample preparation using FIB.

Figure 7 shows EDS elemental maps obtained from the $0.2 \% \mathrm{Si}$ sample after annealing. It can be seen that $\mathrm{Si}$ is depleted in the intermetallic phase layer. The partitioning of $\mathrm{Si}$ is in consistent with a recent study which reported that the Si content detected in the $\delta_{1}$ and $\zeta$ phases is much lower than that in the iron substrate [7]. 

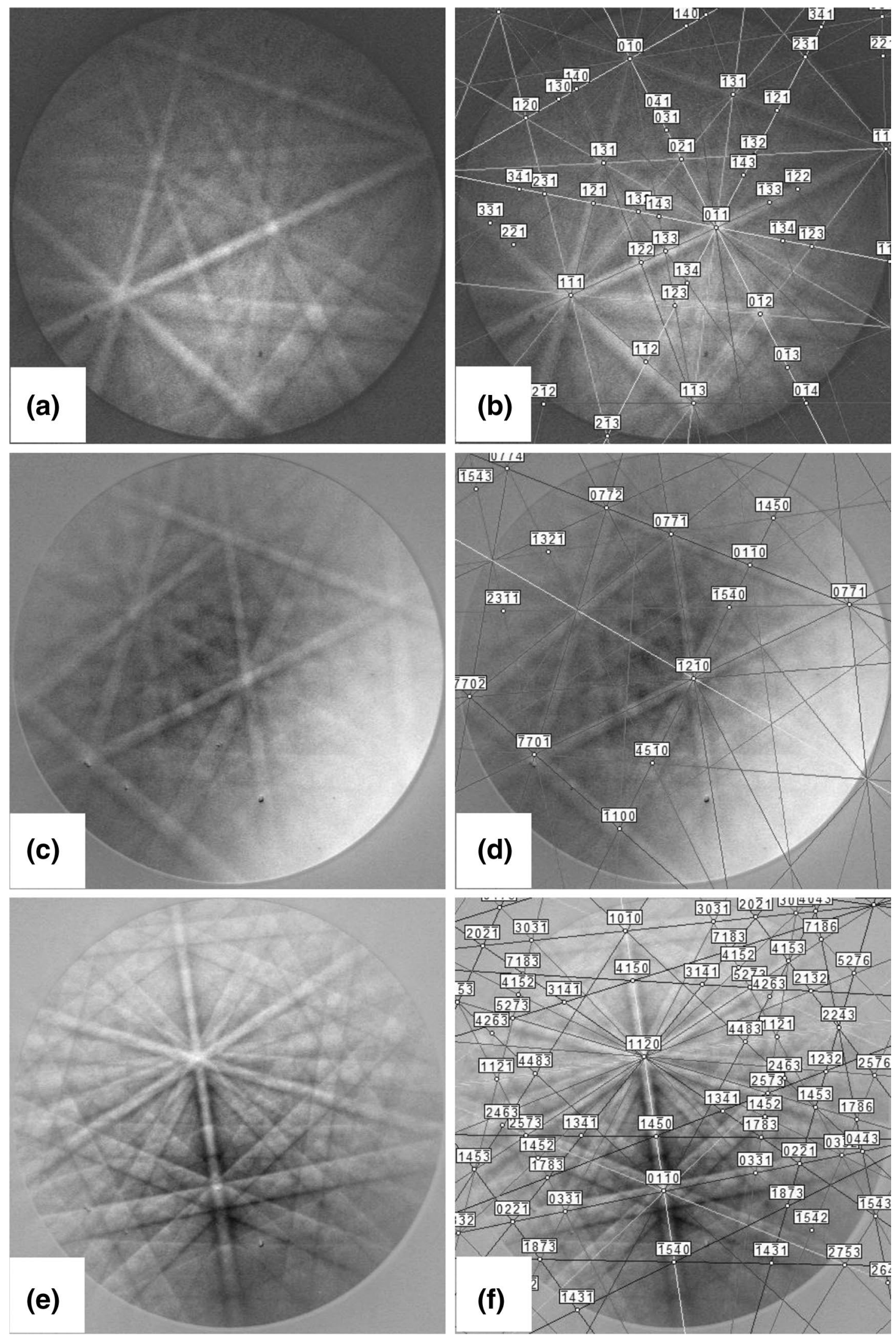
Table 2 Crystallographic symmetry data used for indexing phases in analyzing EBSD patterns

\begin{tabular}{llll}
\hline Phase & $\Gamma$ & $\delta_{1}$ & $\mathrm{n}-\mathrm{Zn}$ \\
\hline $\begin{array}{l}\text { Chemical composition } \\
\text { Space group }\end{array}$ & $\mathrm{Fe}_{3} \mathrm{Zn}_{10}$ & $\mathrm{FeZn}_{7-10}$ & $\mathrm{Zn}$ \\
$\begin{array}{l}\text { Lattice parameter } \\
\mathrm{I}-43 \mathrm{~m}\end{array}$ & $\mathrm{P}_{3} / \mathrm{mmc}$ & $\mathrm{P} 6_{3} / \mathrm{mmc}$ \\
$\begin{array}{l}\text { (Å) } \\
\quad(\AA)\end{array}$ & 9.018 & 12.815 & 2.665 \\
Reflectors used for indexing & - & 57.35 & 4.947 \\
& 033 & 0002 & 0002 \\
& 141 & $0-117$ & $10-10$ \\
& 060 & $1-210$ & $10-11$ \\
& 444 & $02-27$ & $10-13$ \\
& 363 & $1-327$ & $11-20$ \\
& 093 & $03-30$ & $11-22$ \\
& & $1-2110$ & $20-21$ \\
& & $1-21-14$ & $20-23$ \\
& & & $21-31$ \\
\hline
\end{tabular}

\subsection{The effect of Si on the alloying reaction in galvanizing/annealing process}

It has been confirmed in the present study that the addition of $\mathrm{Si}$ to the iron substrate reduces the amount and the thickness of the $\delta_{1}$ phase layer at the substrate/liquid interface. It has also been found that the Si addition changes a manner of intermetallic phase formation such that the phase is dispersed as grains within the $\mathrm{Zn}-0.2 \%$ Al matrix. The effects of Si on the formation of the $\delta_{1}$ intermetallic phase are discussed below.

Several mechanisms were reported to explain the effect of $\mathrm{Si}$ to retard the alloying reaction. One mechanism is related to the decomposition of $\mathrm{Fe}_{2} \mathrm{Al}_{5}$ phase which is generally accepted to trigger the outburst reaction. Yasui et al. reported that retardation of the outburst reaction can be explained by a slower decomposition rate of the $\mathrm{Fe}_{2} \mathrm{Al}_{5}$ phase by the solid solution of $\mathrm{Si}$ into the phase $[6$, 14]. This mechanism is based on the report that Si occupies the vacancy sites of the $\mathrm{Fe}_{2} \mathrm{Al}_{5}$ phase structure [15-18], which may reduce the rate of $\mathrm{Al}$ diffusion, resulting in a slowed decomposition rate of the phase. Another mechanism is the suppression of diffusion of Fe and $\mathrm{Zn}$ in the $\delta_{1}$ phase by solid solution of $\mathrm{Si}$ in the phase. This thought was encouraged by diffusion couple experiments [19] showing a slower growth rate of the phase in the presence of $\mathrm{Si}$ and the literatures $[9,20]$ which reported on the solubility of Si by 1 at.\% in the $\delta_{1}$ phase in the Fe-Zn-Si ternary phase

Fig. 6 STEM image and corresponding EDS maps taken from A and $B$ in a pick-up thin plate of the $0.2 \%$ Si sample after hot-dip galvanizing. Horizontal lines are formed milling with FIB and bright area on the right side in the area $\mathrm{A}$ is a hole
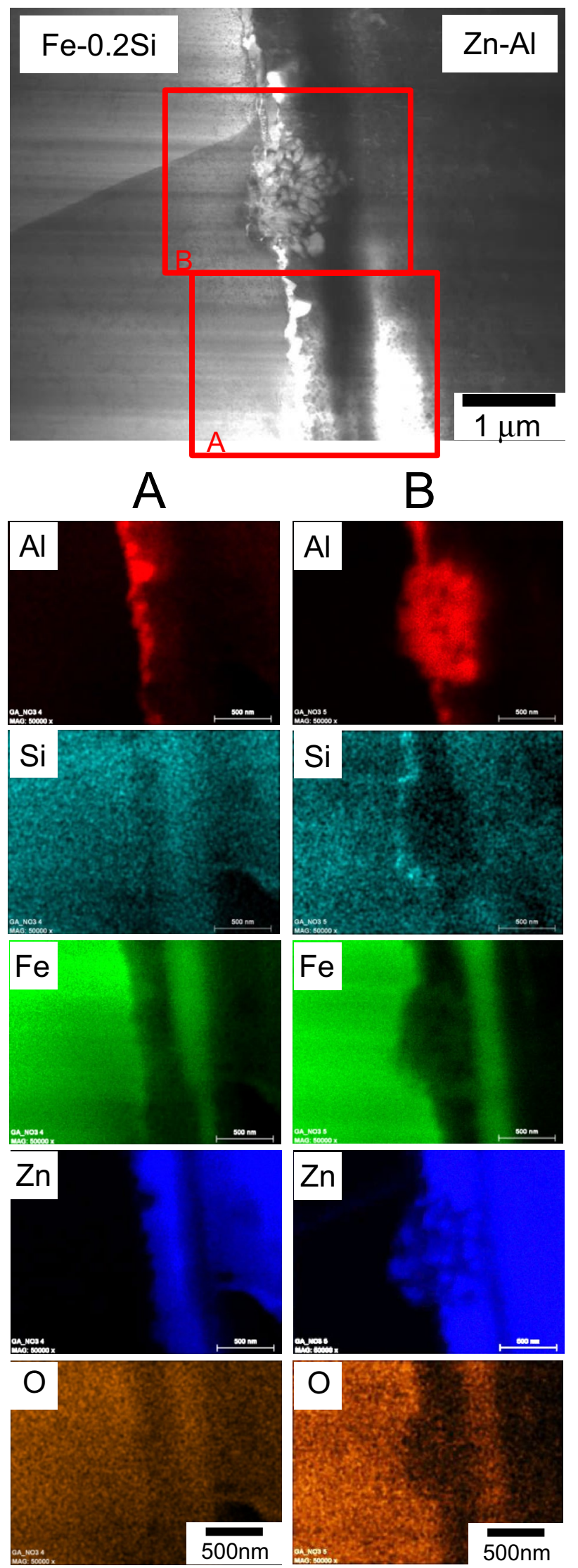

\section{SN Applied Sciences}



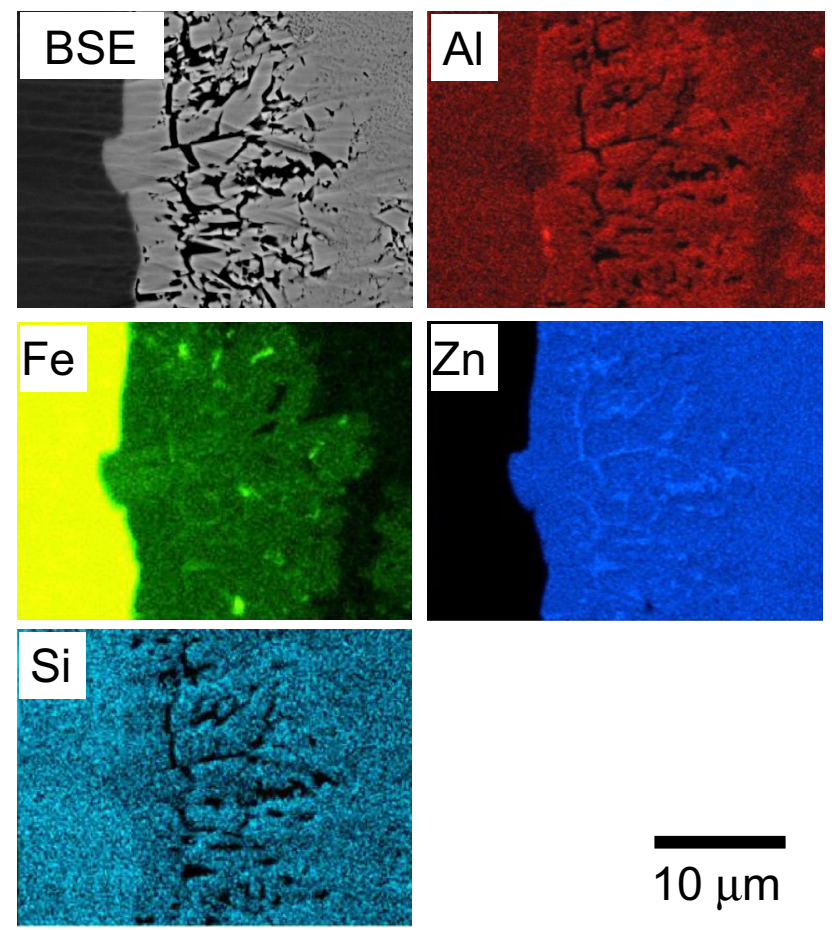

Fig. 7 Backscattered electron (BSE) image and corresponding EDS elemental maps obtained from the $0.2 \%$ Si sample after annealing

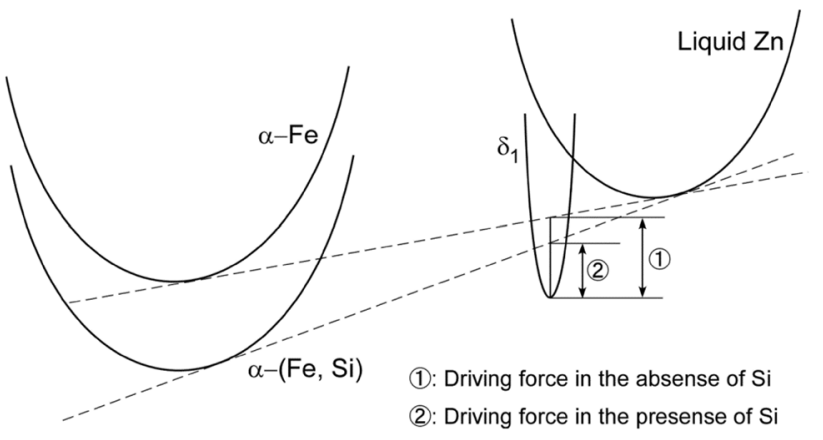

Fig. 8 Schematic illustration showing an effect of Si addition on thermodynamic stability of the phases and the driving force for the nucleation of the $\delta_{1}$ phase

diagram. The validity of this mechanism is, however, in question because the present study which shows that the $\mathrm{Si}$ content detected in the intermetallic phase is negligible.

The effect of $\mathrm{Si}$ on the alloying reaction is considered in terms of thermodynamic viewpoint below. The microstructural characterization in the present study and in our previous work indicates that Si tends to partition less into the $\delta_{1}$ phase than into the ferrite phase in the substrate. This finding is supported by a report by Wang et al. [21], which shows that the partition coefficient of Si between the $\delta_{1}$ and the a phases $\left(k \delta^{1 / a}\right)$ is $\sim 0.06$. Based on the $\mathrm{Si}$ partitioning behavior, one can assume that Si thermodynamically stabilizes the ferrite phase against the $\delta_{1}$ phase and thereby reducing the driving force for the nucleation of the intermetallic phase at the substrate/liquid interface. This effect is schematically illustrated in Fig. 8. This scenario may qualitatively explain the formation of a reduced amount of the intermetallic phase attached to the steel substrate and a dispersion of the phase within the $\mathrm{Zn}$ matrix in the presence of $\mathrm{Si}$ in the substrate (Fig. 2). Quantitative thermodynamic studies might be important to understand the effect of Si on the alloy in reaction in more accurate way.

\section{Summary}

In the present paper effects of Si on the formation of intermetallic phases in the alloying reaction between an iron substrate and liquid $\mathrm{Zn}$ containing $0.2 \mathrm{wt} \% \mathrm{Al}$ and partitioning of $\mathrm{Si}$ between the phases were investigated to understand the alloying reactions during hot-dip galvanizing and annealing of Si doped steels. The main results obtained are as follows:

1. The addition of Si to an iron substrate was found to scarcely influence the formation and morphology of $\mathrm{Fe}_{2} \mathrm{Al}_{5}$ intermetallic phase layer but to reduce the amount of $\delta_{1}-\mathrm{FeZn}_{7-10}$ intermetallic phase layer at the substrate/liquid interface and to disperse the phase as grains in the $\mathrm{Zn}-0.2 \mathrm{wt} \% \mathrm{Al}$ matrix.

2. STEM-EDS analysis demonstrates that Si partitions less into the $\mathrm{Fe}_{2} \mathrm{Al}_{5}$ and the $\delta_{1}$ phases than into the iron substrate (ferrite) phase. Enrichment of $\mathrm{Si}$ around an Si-depleted Fe-Zn intermetallic phase product was also observed in the beginning of the alloying reaction.

3. The observed effects of $\mathrm{Si}$ on the intermetallic phase formation may be explained by a difficulty in nucleating the $\delta_{1}$ phase at the substrate/liquid interface.

Acknowledgements This study was financed and assisted by the Iron and Steel Institute of Japan in the research activity on "Effect of Si addition to steel substrate on coating properties of galvannealed steel sheets". The author appreciates Prof. T. Takasugi at Osaka Prefecture University and Prof. K. Tsuzaki at National Institute for Materials Science (Currently at Kyusyu University) for their support. The author also thanks Ms. Y. Hara and Prof. T. Hara for their help in using microscopes. 


\section{Compliance with ethical standards}

Conflict of interest The authors declare that they have no conflict of interest.

\section{References}

1. Saginuma M, Watanabe T (2008) Daigaku-Kyozai Tekko-Kogaku ZairyoHen Hyomen shori-Kohan. JFE 21st Century Foundation, Tokyo, p 227 (in Japanese)

2. Inagaki J, Sakurai M, Watanabe T (1993) Alloying reactions and coating microstructure in continuous galvanizing and galvannealing process. Tetsu-to Hagané 79:1273

3. Takata N, Takeyama M (2014) Effect of steel microstructure on solid Fe/liquid $\mathrm{Zn}$ interface reaction in hot-dipped $\mathrm{Zn}$ galvanized steels. Tetsu-to-Hagané 100:1172

4. Tobiyama Y (2015) Doctoral thesis. Tokyo Institute of Technology (in Japanese)

5. Tobiyama Y, Kato C (2003) Effect of the substrate compositions on the growth of Fe-Al interfacial layer formed during hot dip galvanizing. Tetsu-to-Hagané 89:38

6. Yasui T, Nakazawa M, Miyasaka A (2007) Factors affecting galvanealing behavior of si-containing steel sheets. In: Proceedings of 7th international conference on zinc and zinc alloy coated steel sheet (GALVATECH'07). ISIJ, Tokyo, p 493

7. Kobayashi S (2017) Effects of Si solid solution in Fe substrate on the alloying reaction between Fe substrate and liquid $\mathrm{Zn}$. Tetsu-to-Hagané 103:38

8. Kobayashi S (2017) Effects of Si solid solution in Fe substrate on the alloying reaction between Fe substrate and liquid Zn. ISIJ Int 57:2214

9. Perrot P, Dauphin JY (1988) Calculation of the Fe-Zn-Si phasediagram between 773-K and 1173-K. Calphad 12:33
10. Villars P Pearson's Handbook Desk Edition Crystallographic Data for Intermetallic Phases (1997) ASM International, Materials Park, $\mathrm{OH}$

11. Bastin G, Van Loo F, Rieck G (1976) Texture in delta-(Fe-Zn) layer formed during hot dip galvanizing. Z. Metallkd 67:694

12. Hong MH, Saka H (1997) Transmission electron microscopy of the iron-zinc delta(1) intermetallic phase. Scr Mater 36:1423

13. Okamoto NL, Tanaka K, Yasuhara A, Inui H (2014) Structure refinement of the $\delta 1 \mathrm{p}$ phase in the $\mathrm{Fe}-\mathrm{Zn}$ system by singlecrystal X-ray diffraction combined with scanning transmission electron microscopy. Acta Cryst B70:275

14. Chen ZW, Sharp RM, Gregory JT (1992) The effect of silicon in steel on the growth of intermetallic phases during hot dipping in a Zn-5-percent A1 melt. Surf Coat Technol 53:283

15. Eggeler G, Auer W, Käsche H (1986) On the influence of silicon on the growth of the alloy layer during hot dip aluminizing. J Mater Sci 21:3348

16. Takata N, Nishimoto M, Kobayashi S, Takeyama M (2015) Growth of $\mathrm{Fe}_{2} \mathrm{Al}_{5}$ phase on pure iron hot-dipped in $\mathrm{Al}-\mathrm{Mg}$-Si alloy melt with Fe in solution. ISIJ Int 55:1454

17. Takata N, Nishimoto M, Kobayashi S, Takeyama M (2015) Crystallography of $\mathrm{Fe}_{2} \mathrm{Al}_{5}$ phase at the interface between solid Fe and liquid Al. Intermetallics 67:1

18. Takata N, Tsukahara T, Kobayashi S, Takeyama M (2016) Microstructure control of dual-phase steels through hot-dip Al-Mg-Si alloy coating process. ISIJ Int 56:319

19. Lichti KA, Niessen $P$ (1987) The effect of silicon on the reactions between iron and ZETA-(FeZn13). Z Metallkd 78:58

20. Su X, Tang NY, Toguri JM (2001) $450^{\circ} \mathrm{C}$ isothermal section of the Fe-Zn-Si ternary phase diagram. Can Metall Q 40:377

21. Wang J, Su X, Yin F, Li Z, Zhao M (2005) The $480^{\circ} \mathrm{C}$ and $405^{\circ} \mathrm{C}$ isothermal sections of the phase diagram of Fe-Zn-Si ternary system. J Alloys Compd 399:214 